\section{BREAST ABSCESS}

\author{
BY
}

IAN C. S. KNIGHT, M.B., F.R.C.S.Ed.

Senior Registrar, the Royal Infirmary, Edinburgh

AND

BERNARD NOLAN, M.B., F.R.C.S., F.R.C.S.Ed. Senior Registrar, the Royal Infirmary, Edinburgh

The advent of penicillin produced a dramatic change both in the seriousness and in the duration of illnesses due to Staphylococcus aureus infections. The problem of hand infections became less serious and puerperal mastitis responded in almost every case to conservative means (Jeffrey, 1947). Hand infections are still amenable to antibiotic therapy, but puerperal mastitis is no longer responding as well as the early results had led us to expect. Early in 1957 several cases of breast abscess which had received antibiotics ran an unduly protracted course. This led us to investigate the material which forms the subject of this paper.

\section{The Investigation}

During 1957 we studied 100 consecutive cases of puerperal breast abscess which required surgical treatment. All but two of the patients were delivered in hospital. Ninety-nine breast-fed their babies initially. The single exception was because the baby was transferred to a surgical unit for the treatment of a congenital deformity.

The lactational histories of 200 deliveries occurring in general practice in the area during the same period were reviewed.

\section{Breast-feeding}

Duration.-In this area the value of breast-feeding is stressed at the antenatal clinics and during the mother's stay in hospital. Despite this, 20 patients stopped breast-feeding while still in hospital and a further 30 within five days of leaving hospital. Of the two delivered at home, one breast-fed her child for three days and the other for 28 days. Sixty-four patients had given up breast-feeding before the breast became inflamed, and the remaining 36 stopped because of the inflammation. The commonest reasons given for stopping breast feeding in the first group were "cracked nipples" (25 patients) and "failure of lactation" (24 patients). As is shown later, the disease had a much shorter course in those patients who claimed that lactation had failed.

Suppression of Lactation. - Eighty-two patients received stilboestrol in varying dosage. The total dose received appeared to have no relation to the effect on lactation, but we received the impression that a high dosage for a short period is more effective than the same total dose spread over a longer period. We found the dosage ranges commonly advocated were too low to suppress lactation completely when it was established. It was necessary to give $15 \mathrm{mg}$. of stilboestrol three times a day to suppress lactation in those patients who were still lactating when first seen. Oestrogenwithdrawal bleeding was noticed by $32 \%$ of patients who had been taking oestrogen before being seen in hospital, but in none was it severe enough to warrant admission to hospital.

\section{Bacteriology}

Sepsis in the Baby.-Infective lesions had been observed in their babies by 46 mothers. Most of these lesions took the form of minor pustules in the skin ; but in some cases there were paronychiae, and one baby developed a breast abscess for which it was admitted for in-patient treatment at a children's hospital.

The causative organism was isolated in every case and tested for its sensitivity to penicillin, streptomycin, chloramphenicol, and oxytetracycline. This was done by the method described by Gould and Bowie (1952). In all cases a pure growth of coagulase-positive Staph. aureus was obtained. The antibiotic resistance rates are shown in Table I and the sensitivity patterns in Table II.

TABLE I.-Antibiotic Resistance Rate in 100 Cases of Puerperal

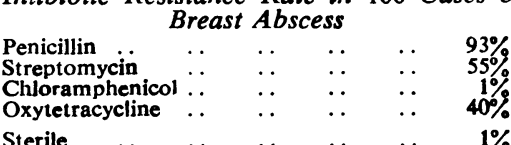

Table II.-Antibiotic Sensitivity Patterns in 100 Cases

\begin{tabular}{|c|c|c|c|c|}
\hline Penicillin & Streptomycin & Chloramphenicol & Oxytetracycline & No. \\
\hline 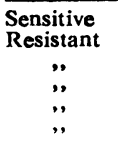 & $\begin{array}{c}\text { Sensitive } \\
\text { Resistant } \\
\text { "" } \\
\text { Sensitive }\end{array}$ & $\begin{array}{c}\text { Sensitive } \\
\text { ", } \\
\text { Resistant } \\
\text { Sensitive } \\
\text { ", }\end{array}$ & $\begin{array}{c}\text { Sensitive } \\
\text { ", } \\
\text { Resistant } \\
\text {," }\end{array}$ & $\begin{array}{r}7 \\
37 \\
14 \\
1 \\
39 \\
1\end{array}$ \\
\hline & Sterile & . & . & 1 \\
\hline
\end{tabular}

Duration of Illness

The duration of the illness was calculated from the first day on which pain was felt in the breast until the incision had healed. This varied from 14 to 148 days, with an average of 50 days. These details, together with the corresponding ones for the periods between onset and the incision, and the incision and healing, are shown in Table III. As most cases were incised on the day

TABLE III.-Duration of Disease

\begin{tabular}{|c|c|c|c|c|}
\hline & \multicolumn{2}{|c|}{$\begin{array}{c}\text { In } \\
\text { Whole Series }\end{array}$} & \multicolumn{2}{|c|}{$\begin{array}{l}\text { In } 24 \text { Cases with } \\
\text { Failure of Lactation }\end{array}$} \\
\hline & Range & Average & Range & Average \\
\hline $\begin{array}{l}\text { No. of days from onset until } \\
\text { incision . } \\
\text { No. of days from incision } \\
\text { until healing } \\
\text { No. of days from onset until } \\
\text { healing } \ldots\end{array}$ & $\begin{array}{r}4-134 \\
4-103 \\
14-148\end{array}$ & $\begin{array}{l}15 \\
35 \\
50\end{array}$ & $\begin{array}{r}5-42 \\
4-63 \\
14-71\end{array}$ & $\begin{array}{l}15 \\
19 \\
34\end{array}$ \\
\hline
\end{tabular}

\begin{tabular}{|c|c|c|c|c|}
\hline \multirow{2}{*}{\multicolumn{2}{|c|}{ Antibiotic }} & \multirow{2}{*}{$\begin{array}{c}\text { No. of } \\
\text { Patients }\end{array}$} & \multicolumn{2}{|c|}{ Days of Treatment } \\
\hline & & & Range & Average \\
\hline $\begin{array}{l}\text { Penicillin . . } \\
\text { Streptomycin } \\
\text { Chloramphenicol } \\
\text { Oxytetracycline .. } \\
\text { Chlortetracycline }\end{array}$ & $\begin{array}{l}\cdots \\
\cdots \\
\cdots \\
\cdots\end{array}$ & $\begin{array}{r}86 \\
8 \\
8 \\
11 \\
3\end{array}$ & $\begin{array}{l}1-17 \\
5-15 \\
5-15 \\
4-25 \\
4-8\end{array}$ & $\begin{array}{l}6 \cdot 5 \\
8 \cdot 0 \\
8.0 \\
6 \cdot 0 \\
6 \cdot 3\end{array}$ \\
\hline
\end{tabular}

they were first seen, the average interval between the onset and the incision corresponds closely with the average time which elapsed before the patients were referred for hospital treatment. In 24 cases in which breast-feeding was stopped because of failure of lactation the average time between the onset of symptoms and the first incision was the same as that of the whole series-that is, 15 days-but the time from incision until healing occurred was only 19 days.

Recurrence of Abscesses.-A further abscess developed in the same breast in 24 patients and in the opposite breast in 10 . In retrospect it appeared that these abscesses were associated with the recurrence of 
lactation in patients in whom lactation appeared to be so satisfactorily suppressed when they were first seen that they were given no further stilboestrol.

\section{Treatment}

The antibiotics used and the average duration of treatment are shown in Table IV. The interval between the onset of symptoms and the start of antibiotic therapy varied from one to 17 days, with an average for the series of three days.

In every case antibiotics were stopped when the diagnosis of a breast abscess was made. Stilboestrol, in a dosage of $45 \mathrm{mg}$. daily in divided doses, was given if milk could be expressed from the breasts.

The breast was incised as soon as the presence of pus was diagnosed. In the exceptional doubtful case the diagnosis was confirmed by aspiration with a wide-bore needle. A soft rubber drain was inserted and left in position for 24-48 hours; thereafter the cavity was lightly packed with gauze soaked in eusol.

In the later cases we used a circumferential incision of the skin as advocated by Haagensen (1956) for the excision of simple tumours. Dissection in the mammary tissue itself was in the line of the ducts. These incisions proved adequate for drainage and postoperative treatment and healed with a better cosmetic result than the more conventional radial incision.

\section{Discussion}

Breast abscess appears to be a more protracted disease than in pre-antibiotic days, when the lesion healed in three to four weeks (Macpherson, 1943).

When the organism is resistant to the antibiotic used the pathological features are modified unfavourably. Tissue necrosis and pus formation are retarded, while repair proceeds uninhibited. A thick fibrous wall forms around the abscess. This delays resolution and prevents the cavity collapsing after incision. In extreme cases the abscess is rendered quiescent and the residual mass resembles a carcinoma (Rose, 1956). A further result of this increased fibrosis is the tendency to produce unsightly shrunken breasts.

Another clinical variety is a diffuse oedematous inflammation of the breast which persists for many days before any localization or pus formation becomes apparent. Continuation of antibiotic therapy did not seem to help in this type of lesion, and more satisfactory results were obtained by withholding further antibiotics and applying local heat.

From a review of hospital records in Edinburgh it is estimated that in 1957 between 3 and $4 \%$ of all women delivered developed breast abscesses requiring hospital treatment.

To estimate the proportion of puerperal breast infections which resolve without hospital treatment the post-natal histories of 200 consecutive deliveries which occurred in the General Practice Teaching Unit of

TABLE V.-Incidence of Mastitis and Breast Abscess in 200

\begin{tabular}{|c|c|c|c|c|c|c|}
\hline & & \multirow{2}{*}{ No. } & \multicolumn{2}{|c|}{ Breast Infoctions } & \multicolumn{2}{|c|}{ Breast Abscess } \\
\hline & & & No. & $\%$ & No. & $\%$ \\
\hline $\begin{array}{l}\text { Home confinements } \\
\text { Hospital ", }\end{array}$ & $\therefore$ & $\begin{array}{r}70 \\
130\end{array}$ & $\begin{array}{r}5 \\
20\end{array}$ & $\begin{array}{r}7 \cdot 1 \\
15 \cdot 4\end{array}$ & $\begin{array}{l}2 \\
4\end{array}$ & $\begin{array}{l}2 \cdot 8 \\
3 \cdot 1\end{array}$ \\
\hline Total & .. & 200 & 25 & $12 \cdot 5$ & 6 & 3.0 \\
\hline
\end{tabular}

Edinburgh University were studied. Of these, $35 \%$ were delivered at home (Table V). Only one case in four which developed mastitis progressed to abscess formation. The incidence of the latter was the same as that calculated for the whole region.

The incidence of breast infections following hospital deliveries was more than double that following home confinements (Table V). This was associated with the heavy colonization of the baby's nasopharynx with organisms from the environment in which it spends the first few days of life.

These organisms were the same as those recovered from the breast abscesses but were different from those carried in the mother's nares.

An important aetiological factor in breast infections is engorgement with milk. This commonly results from the stopping of breast-feeding without adequate measures being taken to suppress lactation and empty the breasts. At least one-third of our patients had stopped breast-feeding because they were opposed to it. They had breast-fed their babies reluctantly while in the maternity hospital, but gave up as soon as they left. Few sought medical advice about suppressing lactation.

These findings suggest that breast-feeding should not be forced on unwilling mothers. These patients would benefit more from proper instruction in bottle-feeding while in hospital.

When engorgement has occurred it is probably best managed by gentle manual expression of the milk, as described by Waller (1946). Breast pumps or the "humalactor" may be used if available (Ratcliff, 1951). Engorgement occurring during lactation usually responds to a short course of oestrogen combined with manual expression.

Continued lactation without engorgement may delay healing. As shown in Table IV, the healing-time in cases where lactation failed was shorter than in the series as a whole.

Successful conservative treatment includes the use of an antibiotic to which the organisms are sensitive. Until the sensitivity of the causative organism has been determined it should be assumed that it is the same as that of the environmental organisms of the maternity unit concerned. In this region chloramphenicol was the drug of choice. In the series from the General Practitioner Teaching Unit 10 of the 11 cases treated with chloramphenicol responded satisfactorily (Table VI).

\begin{tabular}{|c|c|c|c|}
\hline \multicolumn{2}{|l|}{ Antibiotic } & No. Treated & No. Recovering \\
\hline $\begin{array}{l}\text { Penicillin .. } \\
\text { Chloramphenicol } \\
\text { Erythromycin } \\
\text { Penicillin and streptomyci } \\
\text { None }\end{array}$ & $\begin{array}{l}\ldots \\
\cdots \\
\cdots\end{array}$ & $\begin{array}{r}10 \\
11 \\
1 \\
2 \\
1\end{array}$ & $\begin{array}{r}5 \\
10 \\
1 \\
2 \\
1\end{array}$ \\
\hline Total & $\ldots$ & 25 & 19 \\
\hline
\end{tabular}

We have estimated that the cost per patient of drugs, dressings, and nursing services was over $£ 10$, although all were treated as out-patients.

\section{Conclusion}

From these observations we feel justified in making the following recommendations. (1) Every measure shuuld be taken to prevent colonization of the baby by antibiotic-resistant staphylococci. (2) Mothers who 
remain opposed to breast-feeding despite full propaganda should be allowed to bottle-feed their babies and receive instruction in the correct technique for doing this. (3) If breast-feeding is stopped, lactation should be vigorously suppressed under medical supervision. We would suggest that stilboestrol be given in a dosage of $45 \mathrm{mg}$. three times a day. The breast should be emptied regularly by manual expression and lumpy collections dispersed by gentle centripetal massage. (4) An antibiotic should be given if infection is suspected. If there is no local response after 48 hours the antibiotic should be stopped. Prolonging antibiotic treatment in the absence of a response leads to excessive fibrosis and protraction of the disease. (5) The antibiotic of choice in this series was chloramphenicol.

\section{Summary}

One hundred consecutive cases of puerperal breast abscess requiring hospital treatment were studied. It was shown that the duration of the disease has increased compared with earlier reports from the same hospital (Macpherson, 1943). This increase seems to be due to the widespread use of antibiotics.

Very high resistance rates to antibiotics were shown. The failure of antibiotic treatment was largely due to this resistance.

The modification of the pathology of the disease when treated with antibiotics to which the organism is not fully sensitive is discussed.

The importance of adequate suppression of lactation and of avoidance of breast engorgement in the prevention of infection in those who stop breast-feeding is stressed.

Recommendations to reduce the incidence and duration of the disease are made.

This work was made possible by the help and co-operation of Sister Gordon and the medical and nursing staff of the surgical out-patient department of the Royal Infirmary, Edinburgh; Dr. Richard Scott and his colleagues of the General Practice Teaching Unit of Edinburgh University; and Dr. J. H. Bowie and Dr. J. C. Gould, who performed the bacteriological examinations. We also thank Mr. D. McIntosh and Mr. A. I. S. Macpherson for permission to study cases in their charge.

\section{REFERENCES}

Gould, J. C., and Bowie, J. H. (1952). Edinb. med. J., 59, 178. Haagensen, C. D. (1956). Diseases of the Breast. Saunders, Philadelphia.

Jeffrey, J. S. (1947). Edinb. med. J., 54, 442

Macpherson, A. I. S. (1943). Ibid., 50, 25.

Ratcliff, R. A. (1951). Brit. med. J., 2, 234

Rose, T. F (1956). Med. J. Aust. 2, 567.

Waller, H. (1946). Arch. Dis. Childh., 21, 1.

\section{Medical Memoranda}

\section{Xanthocillin Cream for Local Treatment}

The type of dermatological case for which local antibacterial treatment is required has altered considerably in recent years. Impetigo contagiosa and other relatively straightforward superficial infections of the skin are now quite uncommon in the hospital clinic. The eczematous eruptions and cheiropompholyx with gross pyogenic secondary infection often combine lymphangitis, cellulitis, lymphadenopathy, and some degree of systemic disturbance, and in these cases a systemic antibiotic is usually indicated ; local treatment then aims at drainage of pus and anti-eczematous rather than antibacterial measures.

There remains a third group of very difficult conditions comprising some types of seborrhoeic dermatitis, particularly those with a tendency to flexural distribution, to weeping, and to superficial folliculitis; intertrigo, particularly with weeping and the development of fissures in the flexures; and varicose (stasis) dermatitis in which infection often plays an important though not the primary part. The role of bacterial infection in these disorders is difficult to assess, but antibacterial applications often produce striking improvement. Indeed, it is in this type of case that local antibiotic treatment is most used at the present time.

Cultures made from the affected surfaces yield pathogens the antibiotic sensitivities of which can be determined. The application of the appropriate antibiotic will frequently be followed by improvement, but all too often the condition relapses after a week or two. Further cultures now reveal a fresh pathogen, this time resistant to the antibiotic which has been used. Because of this the choice of antibiotic according to the results of cultures does not always give the best therapeutic results although it seems logical. Indeed, the use of the "wrong" antibiotic sometimes gives better clinical results than the "right" one.

It is common for these eruptions to become very much worse when a new treatment is applied. This aggravation is sometimes due to allergic hypersensitivity to a fresh antibiotic, but more often it appears to be a non-specific intolerance which at another time, in the same patient, would not occur. This unpredictable non-specific intolerance of treatment makes the management of these cases so much the more difficult.

A clinical trial of a new antibiotic cream therefore presents considerable difficulties. The cream has to be used chiefly in cases of the third group, mentioned above, where the therapeutic results are seldom immediate or clear-cut. Individual cases vary a great deal and may be difficult to classify, so that the selection of cases for treatment is difficult and the arrangement of controls even more so. Presumably, in order to overcome the difficulty of repeated superinfection, the antibiotic should have as wide a range of action as possible with the least tendency to allow the development of resistant strains. It should also have a low sensitizing index - a property which can be expected to emerge only after use in a considerable number of cases; the likelihood of sensitizing 1 to $2 \%$ of patients treated would be a serious drawback, and it may be necessary to treat 100 to 200 people before this can be appreciated.

\section{XANTHOCILLIN}

Xanthocillin is an antibiotic derived from Penicillium notatum (Rothe, 1954) and has been isolated in the form of yellow crystals which contain two components, $x$ and $y$, in the proportion of about $4: 1$. The chemical properties of the two components are very similar: they are sparingly soluble in water, alcohol, ether, and other common solvents, and stable in normal conditions.

Rothe reported that xanthocillin was not suitable for systemic therapy because of its toxic properties and poor absorption, and so its use is limited to topical application. In vitro tests have shown that most of the common Gram-positive and Gram-negative pathogens, including Proteus and Pseudomonas pyocyanea, are sensitive to xanthocillin, and there is also some suppressive action against Mycobacterium 